\title{
Effect of Incorporating a Biodegradable Ecofriendly Additive in Pursuit of Improved Anti-Corrosion, Microstructure and Mechanical Properties of a Zn-based $\mathrm{TiO}_{2} / \mathrm{TiB}_{2}$ Coating by DAECD Technique
}

\author{
O.S.I. Fayomi, ${ }^{a, b,}{ }^{*}$ A.P.I. Popoola, ${ }^{a}{ }^{\text {L.R. }}$ Kanyane ${ }^{a}$ and T. Monyai ${ }^{a}$ \\ ${ }^{a}$ Department of Chemical, Metallurgical and Materials Engineering, Tshwane \\ University of Technology, P.M.B. X680, Pretoria, South Africa \\ ${ }^{b}$ Department of Mechanical Engineering, Covenant University, P.M.B. 1023, \\ Canaan land, Ota, Nigeria
}

Received December 20, 2016; accepted April 8, 2017

\begin{abstract}
The incorporation of composite and eco-friendly particles or fluids to develop new engineering materials has recently changed the coating world. In this study, a $\mathrm{Zn}-\mathrm{TiO}_{2}$ $\mathrm{TiB}_{2}$ ternary alloy was produced from a sulphate bath on a mild steel substrate. Solanum tuberosum (ST) was later introduced to the bath to evaluate the effect of the organic additive on the ternary alloy. The study was conducted under constant plating time and current density. The fabricated matrix was systematically investigated using scanning electron microscope (SEM) coupled with an energy dispersive spectrometer (EDS) for structural properties. The micro hardness and anti-corrosion properties of the deposits were studied using, respectively, a diamond base micro hardness tester and potentiodynamic polarization method. The anti-wear properties and thermal stability of the electrodeposited alloy were studied using a MTR-300 abrasive tester and an isothermal furnace at $250^{\circ} \mathrm{C}$. From the observed result, the coatings presented good stability, especially for $\mathrm{Zn}-\mathrm{TiO}_{2}-\mathrm{TiB}_{2}-\mathrm{ST}$, as compared to the $\mathrm{Zn}-\mathrm{TiO}_{2}-\mathrm{TiB}_{2}$ coating. The addition of ST improved the hardness properties of the matrix from 182.4 to197.2 $\mathrm{HV}$, and the corrosion rate from 0.9805 to $0.7711 \mathrm{~mm} / \mathrm{yr}$. This work established that codeposition of mild steel with $\mathrm{TiO}_{2} / \mathrm{TiB}_{2} / \mathrm{ST}$ is promising in anti-wear and corrosion resistance properties.
\end{abstract}

Keywords: $\mathrm{Zn}-\mathrm{TiO}_{2}-\mathrm{TiB}_{2} ;$ solanum tuberosum (ST); electrodeposition; structural properties.

\section{Introduction}

The potential uses of low carbon steel are numerous, especially in engineering fields, due to its accessibility, reasonable cost and physical properties, such as

\footnotetext{
* Corresponding author. E-mail address: ojosundayfayomi3@gmail.com
} 
durability, weldability and strength [1-3]. It has, however, a low life span, due to its reactivity to moisture, oxygen, humidity and temperature in the area of application, leading to the buildup of rust, which results in failures [4]. The main environmental challenges of mild steel are chemical and mechanical interactions. The mechanical challenge to steel, that often results in the loss of wear life, high friction coefficient and thermal instability, is caused by mechanical interactions of two components in contact with each other [5, 6].

Hence, the need to protect a metal component from this chemical and mechanical catastrophe, so as to reduce unexpected failure in service [7]. One of the best ways to prevent corrosion and mechanical fallout is to apply an anti-corrosion protective coating. A protective coating of a substrate prevents its contact with harsh environments (atmospheric, chemical, etc.) [8,9]. Although many coating methods have been used over decades, to minimize or prevent this challenge, the attentions have increasingly turned on thin film applications that can offer longlasting protection to virtually any substrate $[10,11]$.

Electrodeposition has been found to possess good qualities, such as durability, strength, improved chemical and mechanical wear life with targeted weight ratio in terms of thin film applications. Zinc and zinc alloy coatings have been extensively employed on steel structures and components to shield them from electrochemical reactions and wear in marine and acidic environments [12-14]. In recent times, a shift into binary and ternary alloys, such as $\mathrm{Zn}-\mathrm{Fe}, \mathrm{Zn}-\mathrm{Co}, \mathrm{Zn}$ $\mathrm{Ni}, \mathrm{Zn}-\mathrm{Al}, \mathrm{Zn}-\mathrm{Si}, \mathrm{Zn}-\mathrm{Ti}, \mathrm{Zn}-\mathrm{Cr}, \mathrm{Zn}-\mathrm{TiC}-\mathrm{TiB}_{2}$ and $\mathrm{Zn}-\mathrm{Co}-\mathrm{Ti}$ [15-17] in a single bath, has been undertaken by different authors, in an attempt to obtain a compact and adhered functional coating [18]. This tends to improve the corrosion resistance, wear abrasion and micro-hardness characteristics of steel, as compared to a pure zinc coating.

However, stress initiation, caused by bath contents, is reported to be the challenge of developed coatings over time [18, 19]. Another important consideration is the use of environmental toxic bath solutions that are detrimental to health. In view of this, an attempt to create a local eco-friendly ingredient that could reduce the exorbitant cost of the environmental unfriendliness of formulated baths has necessitated this study [20].

Several studies have reported that anticorrosion and micro hardness properties of the electrodeposited samples can be improved by introducing nontoxic, cheap organic and inorganic additives as fillers to the bath, to create a strong structural bond and reduce stress influence. Such additives are solanum tuberosum, saccharum officinarum, N, N-dimethyldodecylamine and 3,4,5-Trimethoxy benzaldehyde, to mention but a few [21-22]. More so, these fillers, also known as bath enhancers, are said to improve the morphology, decrease porosity and increase corrosion resistance properties [22]. Hence, the need to carry out research in this area, so as to confirm the potential of these local fillers on the developed coating. Therefore, the aim of this work is to study the surface structures, wear abrasion, electrochemical resistance and micro-hardness properties of $\mathrm{Zn}-\mathrm{TiO}_{2}-\mathrm{TiB}_{2} / \mathrm{ST}$ co-deposited alloys on mild steel, with the addition of a bath enhancer. 


\section{Material and methods}

\section{Material preparation}

A plane mild steel sheet of $60 \mathrm{~mm}$ x $60 \mathrm{~mm}$ dimension, with the thickness of 1 $\mathrm{mm}$, was used as a substrate in this research. Other used materials include a zinc plate anode (99.9\% pure) and grinding paper in the order of $60 \mu \mathrm{m}, 120 \mu \mathrm{m}, 400$ $\mu \mathrm{m}, 800 \mu \mathrm{m}$ and $1600 \mu \mathrm{m}$ for surface preparation. An electrodeposition bath solution was prepared using distilled water. Samples were activated by sinking them into a $2 \mathrm{M} \mathrm{HCl}$ solution for 10 seconds, and then rinsing them in distilled water, which is in accordance with [21]. The spectro-chemical analysis of the low carbon steel is presented in Table 1.

Table 1. Spectro-chemical analysis of a mild steel sample.

\begin{tabular}{lcccccccc}
\hline Element & $\mathrm{C}$ & $\mathrm{Mn}$ & $\mathrm{Si}$ & $\mathrm{P}$ & $\mathrm{S}$ & $\mathrm{Al}$ & $\mathrm{Ni}$ & $\mathrm{Fe}$ \\
\hline Composition & 0.15 & 0.45 & 0.18 & 0.01 & 0.031 & 0.005 & 0.008 & 99.166 \\
\hline
\end{tabular}

\section{Solanum tuberosum fluid extraction}

Solanum tuberosum of equivalent weight around $18 \mathrm{~g}$ was selected, peeled, washed and grated into smaller pieces. Then, the smaller pieces were squeezed and de-ionized. The extracted fluid was stored in bottles and refrigerated. Fig. 1 presents the molecular structure of solanum tuberosum.

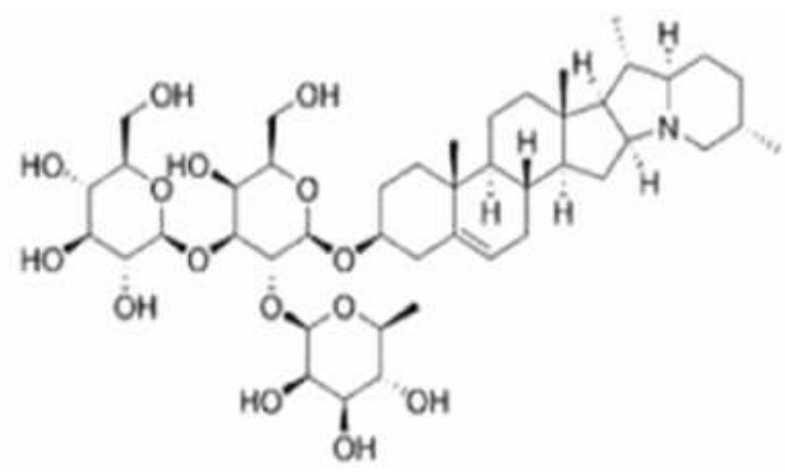

Figure 1. Molecular structure of solanum tuberosum [21].

\section{Preparation of coating formation}

The prepared mild steel samples were dipped in plating. Cathode and anode parts of the process were connected to the D.C. power supply through a rectifier. Electroplating was supported with the applied voltage of $2 \mathrm{~V}$ for $20 \mathrm{~min}$ at $50{ }^{\circ} \mathrm{C}$. Instantly after deposition, the samples were rinsed in distilled water and thereafter they were air-dried. Table 2 presents the electrodeposition bath composition along with the operational conditions used.

\section{Surface characterization}

The surface morphology of the coatings were characterized using a Joel JSM6510 Scanning Electron Microscope, (SEM) built with Energy Dispersive 
Spectroscopy (EDS), and a high resolution optical microscope (OPM) was used to analyze the samples after corrosion and heat-treated samples.

Table 2. Bath composition of $\mathrm{Zn}-\mathrm{TiO}_{2}-\mathrm{TiB} 2 /$ solanum and operating conditions.

\begin{tabular}{cc}
\hline Composition & Mass concentration (g/L) \\
\hline $\mathrm{ZnSO}_{4}$ & 80 \\
$\mathrm{TiO}_{2}$ & 20 \\
$\mathrm{TiB}_{2}$ & 20 \\
Solanum tuberosum & $10(\mathrm{~mL})$ \\
Boric acid & 15 \\
$\mathrm{NaSO}_{4}$ & 20 \\
Glycine & 10 \\
Thiourea & 15 \\
Parameters & \\
pH & 4 \\
Voltage & $2 \mathrm{Volt}$ \\
Time & $20 \mathrm{~min}$. \\
Temperature & $50 \stackrel{\circ}{C}$ \\
\hline
\end{tabular}

\section{Micro hardness characterization}

Micro hardness of the co-deposited matrix was studied by using emco test dura scan micro hardness tester. A $10 \mathrm{~g}$ load was used during the tests and the time was $10 \mathrm{~s}$. The detailed values are, for an average of 3 different indentation measurements, attained from distinct positions.

\section{Abrasive wear studies}

A dry abrasion rig machine (MTR 300) was employed to define the wear mass loss by means of silica sand as wearing medium. The speed used was 200 $\mathrm{rev} / \mathrm{min}$ for $60 \mathrm{~s}$. The initial mass of the electroplated samples was assessed before testing the samples, and the final mass of the samples was also recorded after the dry sliding.

\section{Corrosion studies}

AUTOLAB Galvanostat was employed to investigate the electrochemical behavior of the control sample and coated samples in a $3.65 \mathrm{wt} \% \mathrm{NaCl}$ environment. The polarization measurements were carried from $2.5 \mathrm{~V}$ as start potential to $+1.5 \mathrm{~V}$ as end potential, and the scanning rate was $0.01 \mathrm{~V} / \mathrm{s}$. Graphite served as a counter electrode and $\mathrm{AgCl}$ was the reference electrode. The working electrode was the sample.

\section{Results and discussion}

The summary of the operational conditions during electrodeposition of mild steel samples with $\mathrm{Zn}-\mathrm{TiO}_{2}-\mathrm{TiB}_{2} /$ solanum is presented in Table 3. 
Table 3. Summarized data of ternary $\mathrm{Zn}-\mathrm{TiO}_{2}-\mathrm{TiB}_{2} /$ solanum alloy of electroplated samples.

\begin{tabular}{|c|c|c|c|c|}
\hline $\begin{array}{l}\text { Sample } \\
\text { order }\end{array}$ & & $\begin{array}{c}\text { Time of deposition } \\
\text { (min) }\end{array}$ & $\begin{array}{l}\text { Potential } \\
\text { (V) }\end{array}$ & $\begin{array}{c}\text { Current density } \\
\left(\mathbf{A} / \mathbf{c m}^{2}\right)\end{array}$ \\
\hline As received & - & & 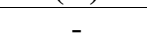 & - \\
\hline $\mathrm{Zn}-\mathrm{TiO}_{2}-\mathrm{TiB}_{2}$ & & 20 & 2 & 3.0 \\
\hline $\mathrm{Zn}-\mathrm{TiO}_{2}-\mathrm{TiB}_{2}$-Solanum & & 20 & 2 & 3.0 \\
\hline
\end{tabular}

\section{Micrographs studies}

SEM/EDS surface characterisation of electroplated mild steel samples

Fig. 2 and 3 displayed the SEM/EDS structure of the electrodeposited samples with and without solanum additives. From all indications, the addition of an additive fluid on $\mathrm{Zn}-\mathrm{TiO}_{2}-\mathrm{TiB}_{2}$ (Fig. 3) shows a flake-like crystalline structure. The structure shows no trace of porosities, cracks and dispatched agglomeration. This implies that possible oriented and adhered crystals were formed. On the other hand, non-homogenous and hexagonal crystals were seen on a $\mathrm{Zn}-\mathrm{TiO}_{2-}$ $\mathrm{TiB}_{2}$ composite coating, which revealed uneven grains refinement (see Fig. 2).

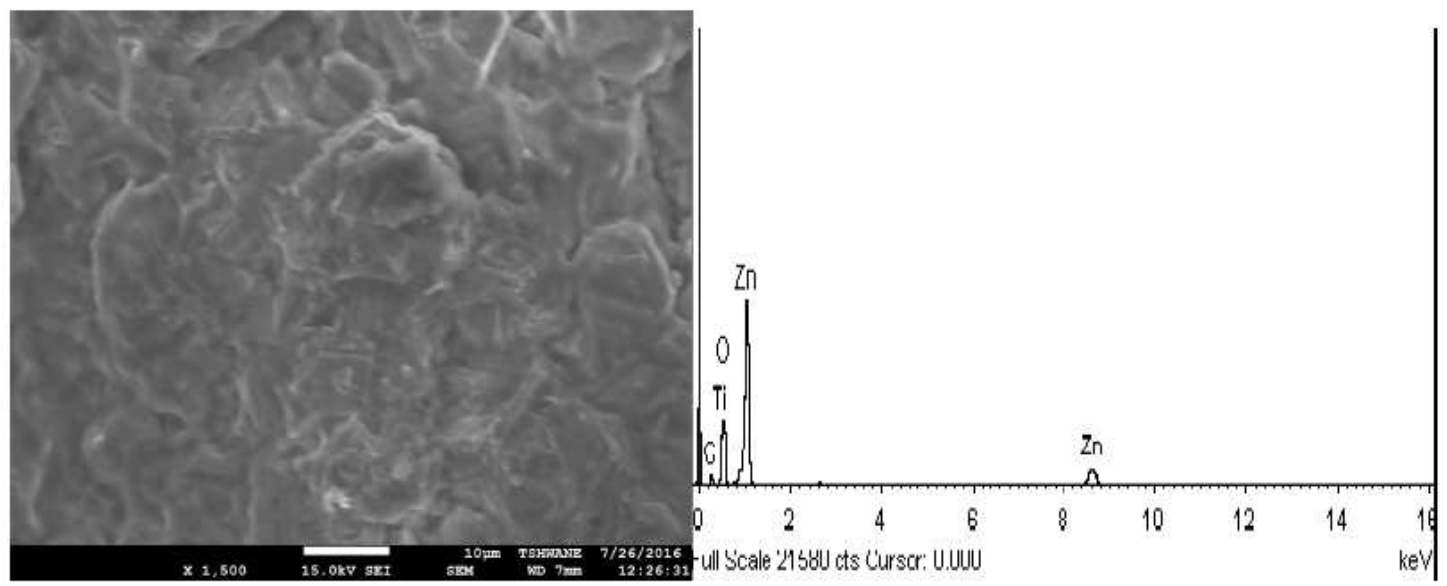

Figure 2. SEM/EDS of $\mathrm{Zn}-\mathrm{TiO}_{2}-\mathrm{TiB}_{2}$ co-deposited sample.

It is noteworthy to mention that a good structural bond is necessary for a suitable solid coating, often caused by the condition of the bath and of its additive [6]. No doubt that the structural behaviour of the coated alloy with solanum has corroborated the study by [8], which has showed that, apart from the process parameter effect, the coating state depends on the bath influence. In addition to the effect of the additive, there is the effort of the embedded composite $\mathrm{TiO}_{2}$ and $\mathrm{TiB}_{2}$ on a zinc rich lattice. The incorporation indicated that a solid precipitation arises within the conjugal existence of the process parameter, embedded particulate and additives. In view of this, the structural changes result from vital coating influences. In addition, in Fig. 2, the EDS elemental distribution without solanum tuberosum confirmed the presence of elements like $\mathrm{Fe}, \mathrm{Si}, \mathrm{Al}, \mathrm{Cl}$, etc., while that of $\mathrm{Zn}-\mathrm{TiO}_{2}-\mathrm{TiB}_{2}-\mathrm{ST}$ also confirmed the presence of elements like $\mathrm{Ti}$, $\mathrm{Zn}, \mathrm{Cl}, \mathrm{Fe}, \mathrm{C}$ and $\mathrm{O}$ on the EDs pattern. The EDS results are in line with our previous studies $[20,21]$. 


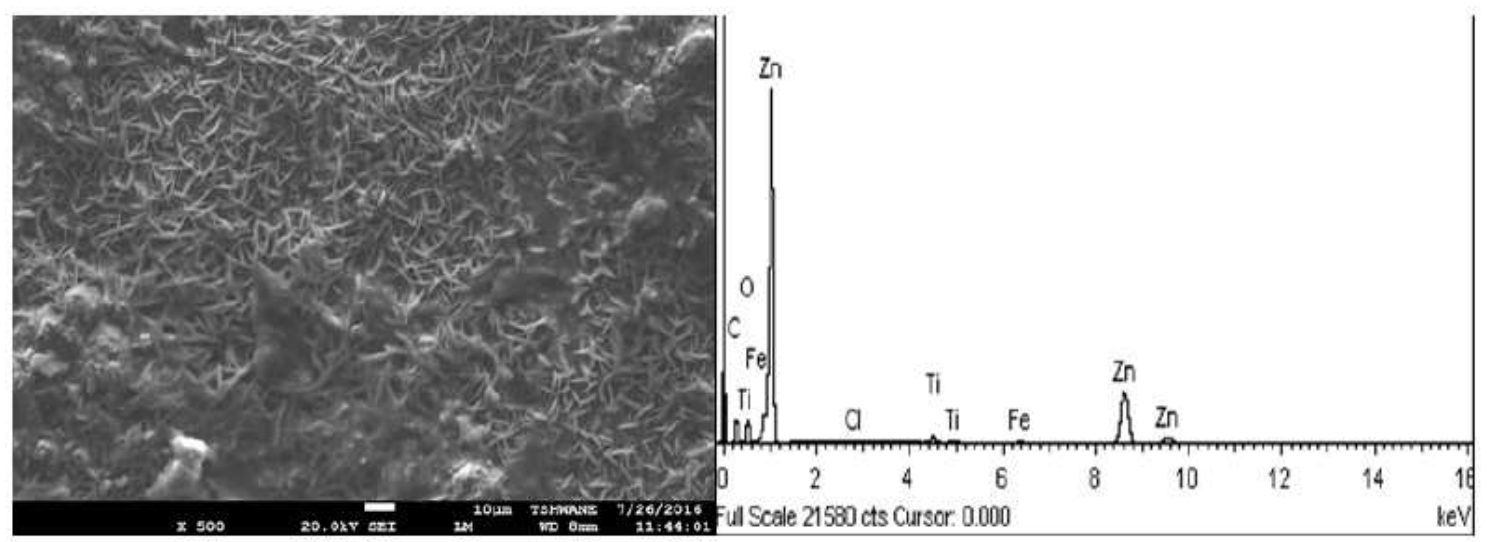

Figure 3. SEM/EDS of $\mathrm{Zn}-\mathrm{TiO}_{2}-\mathrm{TiB}_{2}$-solanum tuberosum co-deposited sample.

\section{Wear study}

The wear loss was carried out using silica sand as the wearing media at a common load of 10 N. Fig. 4 displays the wear loss for the control sample, Zn$\mathrm{TiO}_{2}-\mathrm{TiB}_{2}$ and $\mathrm{Zn}-\mathrm{TiO}_{2}-\mathrm{TiB}_{2}-\mathrm{ST}$ co-deposition.

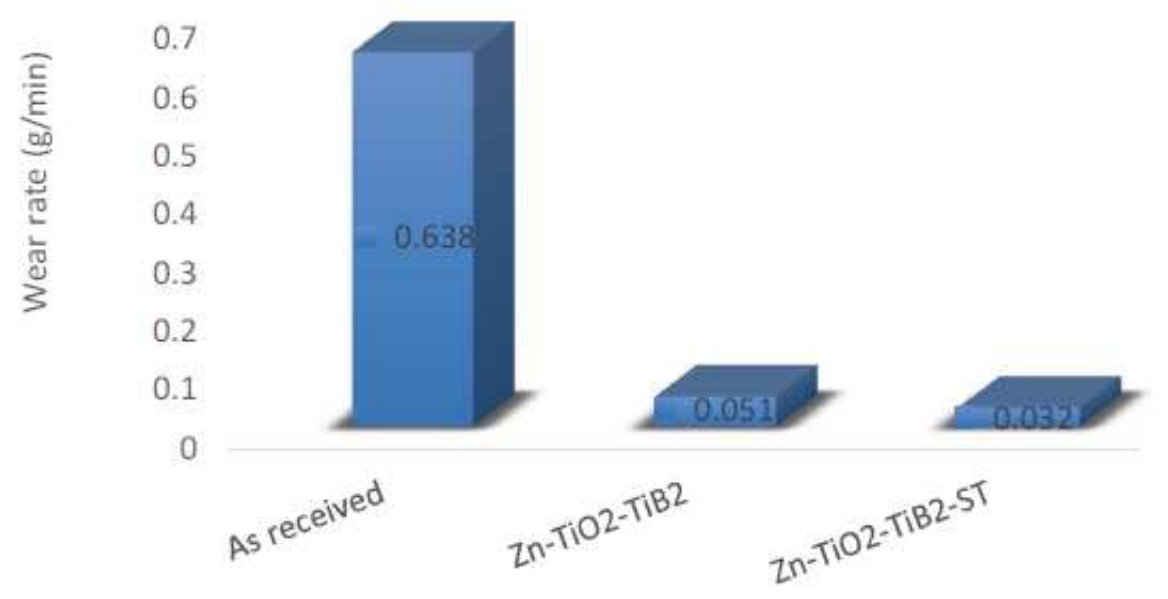

Figure 4. Variation of wear rate of uncoated and coated samples.

The addition of solanum tuberosum on $\mathrm{Zn}-\mathrm{TiO}_{2}-\mathrm{TiB}_{2}$ displayed a reduced mass loss as compared to the as received sample and deposited alloy without solanum. The different wear mass losses for each sample were: $0.638 \mathrm{~g} / \mathrm{min}$ for the asreceived sample; $0.051 \mathrm{~g} / \mathrm{min}$ for the $\mathrm{Zn}-\mathrm{TiO}_{2}-\mathrm{TiB}_{2}$ sample; and $0.032 \mathrm{~g} / \mathrm{min}$ for the $\mathrm{Zn}-\mathrm{TiO}_{2}-\mathrm{TiB}_{2}$ solanum sample. These results put forward that the addition of the bath enhancer and nanoparticles of $\mathrm{TiO}_{2}$ and $\mathrm{TiB}_{2}$ into the $\mathrm{Zn}$ matrix reinforces a protective wall between the coating layer and the wearing medium.

A high resolution optical microscope was used to evaluate the structural characteristics of the coated alloy after a wear study, as presented in Fig. 5. The structures show that the wear-degradation properties of the $\mathrm{Zn}-\mathrm{TiO}_{2}-\mathrm{TiB}_{2}$ (Fig. 5a) coating result in a much higher debris compared to the coating influence by solanum, which shows a low scar along tracks at the interface, as indicated in Fig $5 b$. 

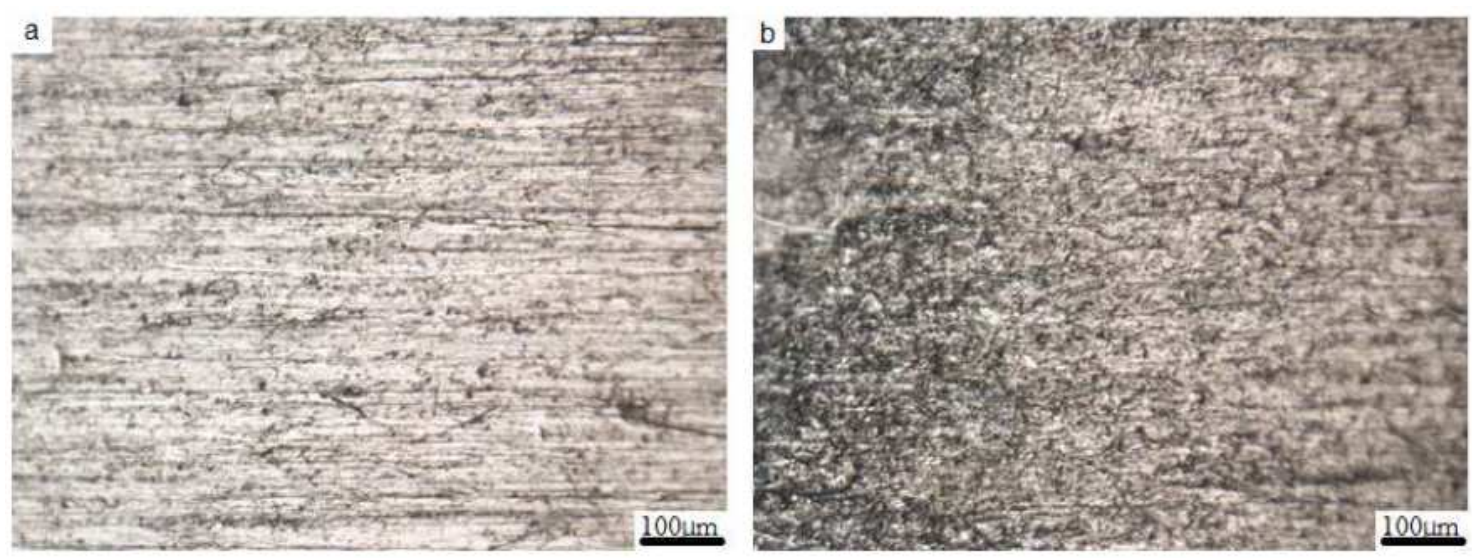

Figure 5. OPM image of a) $\mathrm{Zn}-\mathrm{TiO}_{2}-\mathrm{TiB}_{2}$ b) $\mathrm{Zn}-\mathrm{TiO}_{2}-\mathrm{TiB}_{2}-\mathrm{ST}$ after wear test.

\section{Micro hardness}

The micro-hardness properties of the as-received mild steel substrate, $\mathrm{Zn}-\mathrm{TiO}_{2}-$ $\mathrm{TiB}_{2}$ and $\mathrm{Zn}-\mathrm{TiO}_{2}-\mathrm{TiB}_{2}-\mathrm{ST}$ samples were confirmed using an emco test dura scan and the obtained results are presented in Fig 6.

A significant rise in the micro-hardness value was detected in the $\mathrm{Zn}-\mathrm{TiO}_{2}-\mathrm{TiB}_{2}$ ST matrix. The pure mild steel sample had the micro hardness value of $55 \mathrm{HVN}$, followed by $182.4 \mathrm{HVN}$ for $\mathrm{Zn}-\mathrm{TiO}_{2}-\mathrm{TiB}_{2}$ and $197.9 \mathrm{HVN}$ for the coating with solanum tuberosum. Thermal stability of the electrodeposited samples at $250{ }^{\circ} \mathrm{C}$ had no impact in improving the hardness properties of the deposited mild steel.

According to [22], titanium diboride as a ceramic material has durability and relatively high strength, and it is characterized by relatively high values of hardness and wear resistance. Hence, the presence of $\mathrm{TiO}_{2}$ and $\mathrm{TiB}_{2}$ also has an impact in improving the hardness of plated materials. The rise in the hardness of $\mathrm{Zn}-\mathrm{TiO}_{2}-\mathrm{TiB}_{2}-\mathrm{ST}$ coated samples was due to the presence of solanum tuberosum as an additive, since its structural properties were built up to give it an excellent strength.

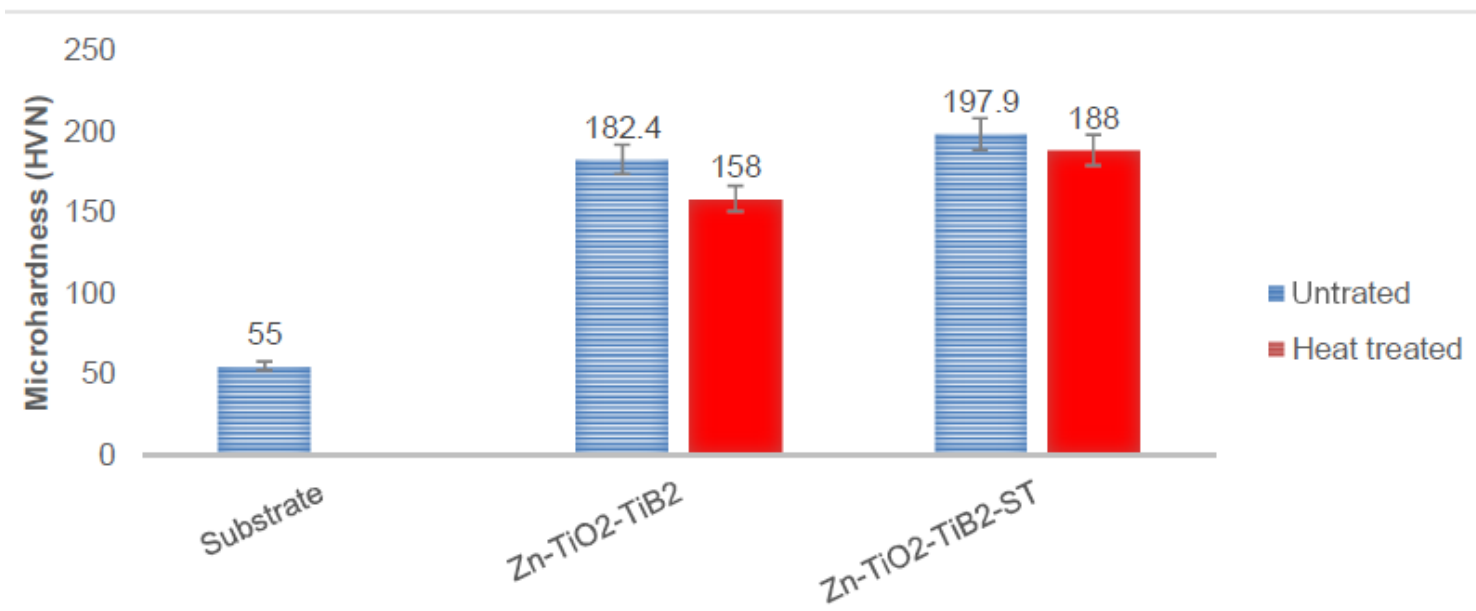

Figure 6. Comparison of the micro hardness of the plated coating for heat treated and untreated samples and mild steel. 
The micrographs of the heat treated samples show compact grains, and there is no evidence of porosities and cracks for both plated samples, as presented in Fig. 7.
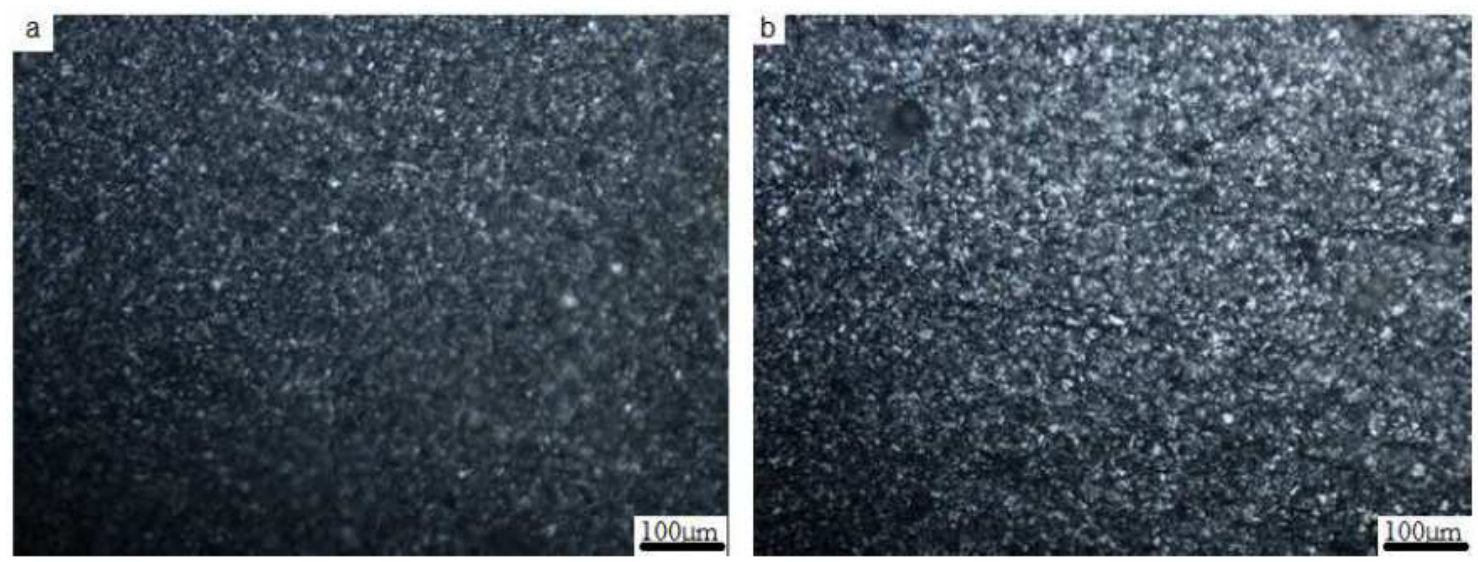

Figure 7. OPM for isothermal stability samples at $250{ }^{\circ} \mathrm{C}$ a) $\mathrm{Zn}-\mathrm{TiO} 2-\mathrm{TiB} 2 \mathrm{~b}$ ) $\mathrm{Zn}-\mathrm{TiO} 2-$ TiB2-ST.

\section{Potentiodynamic polarization studies}

Fig. 8 shows the corrosion behavior of the fabricated composite $\mathrm{Zn}-\mathrm{TiO}_{2}-\mathrm{TiB}_{2}$, $\mathrm{Zn}-\mathrm{TiO}_{2}-\mathrm{TiB}_{2}-\mathrm{ST}$ and as-received samples. $\mathrm{Zn}-\mathrm{TiO}_{2}-\mathrm{TiB}_{2}$ had a little higher potential than the as-received sample, which was never expected. This shows weaker anti-corrosion properties than those of the protective coating. However, on the other hand, the $\mathrm{Zn}-\mathrm{TiO}_{2}-\mathrm{TiB}_{2}-\mathrm{ST}$ matrix witnesses massive passive characteristics with the peak potential values of $-0.254 \mathrm{~V}$, and a corresponding lower corrosion rate, as observed in the Tafel plot represented in Table 4.

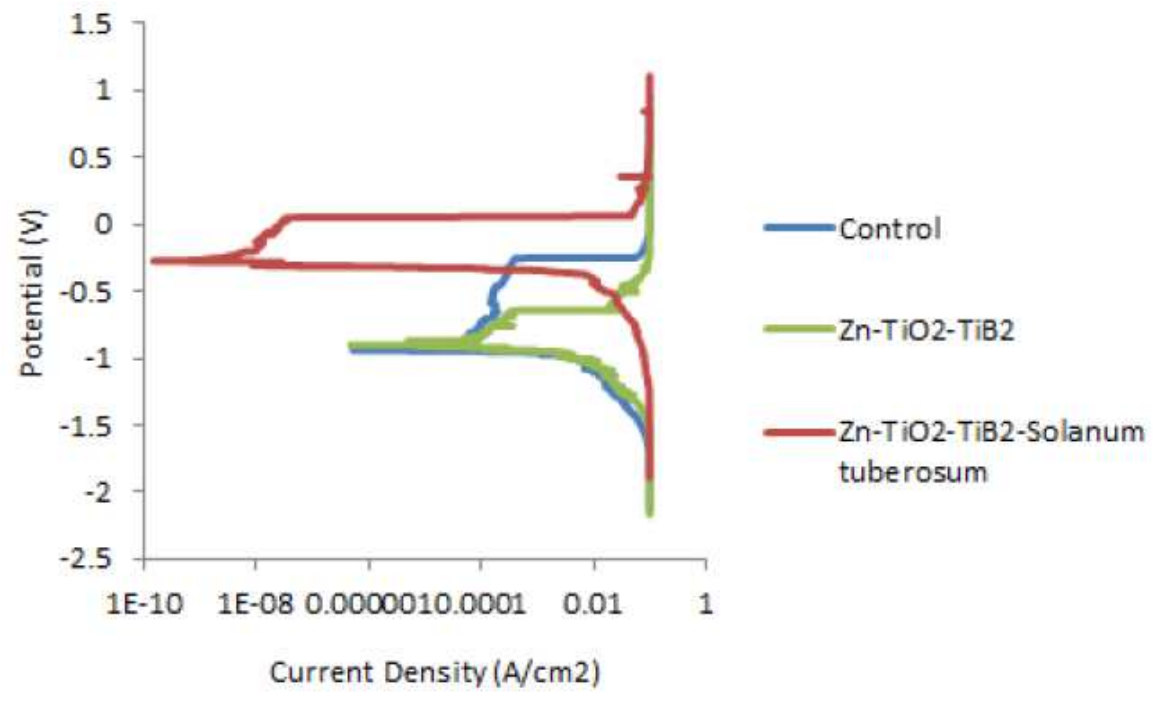

Figure 8. Potentiodynamic polarization for $\mathrm{Zn}-\mathrm{TiO}_{2}-\mathrm{TiB}_{2} / \mathrm{ST}$ deposited mild steel and pure mild steel.

The control sample has a higher corrosion rate of about $4.1 \mathrm{~mm} / \mathrm{yr}$, due to the lack of surface defense against the chloride attack, because a coating protects its substrate by preventing its contact with harsh environments, either atmospheric 
or chemical. Meanwhile, $\mathrm{Zn}-\mathrm{TiO}_{2}-\mathrm{TiB}_{2}$ in the presence of solanum tuberosum resulted in a good decrease in the corrosion current, which is due to the thin layer of $\mathrm{TiO}_{2}, \mathrm{TiB}_{2}$ and the natural additive added to it. On the optical microscope after corrosion (Fig. 9), the coating had a strong protective film, and the micrograph showed that the acidic chloride did not penetrate through. The polarization resistance $(\mathrm{Rp})$ of $\mathrm{Zn}-\mathrm{TiO}_{2}-\mathrm{TiB}_{2}-\mathrm{ST}$ had $246.52(\Omega)$, which was the highest value reached by all the coated samples and the control.

Table 4. Corrosion data obtained for low carbon steel and electroplated samples in $3.65 \% \mathrm{NaCl}$ concentration at $298 \mathrm{~K}$.

\begin{tabular}{|c|c|c|c|c|}
\hline Sample & $\begin{array}{c}\mathbf{I}_{\text {corr }} \\
\left(\mathrm{A} / \mathbf{c m}^{2}\right)\end{array}$ & $\operatorname{RP}(\mathbf{\Omega})$ & $\begin{array}{l}\begin{array}{l}\mathbf{E}_{\text {corr }} \\
(\mathbf{V})\end{array}\end{array}$ & $\begin{array}{c}\text { Corrosion rate } \\
(\mathbf{m m} / \mathbf{y r})\end{array}$ \\
\hline As-received & 0.07040 & 27.601 & -1.110 & 4.1000 \\
\hline $\mathrm{Zn}_{-}-\mathrm{TiO}_{2}-\mathrm{TiB}_{2}$ & 0.000955 & 132.43 & -0.921 & 1.9805 \\
\hline $\mathrm{Zn}-\mathrm{TiO}_{2}-\mathrm{TiB}_{2}-\mathrm{ST}$ & 0.000109 & 246.52 & -0.254 & 0.7711 \\
\hline
\end{tabular}
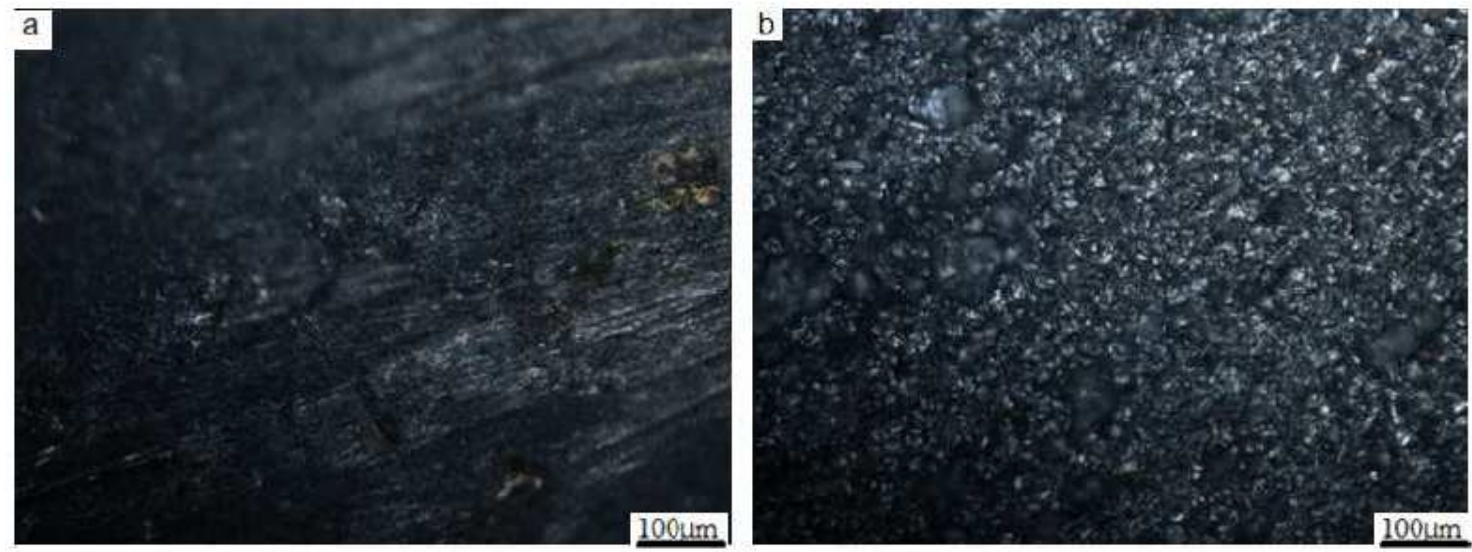

Figure 9. a) $\mathrm{Zn}-\mathrm{TiO}_{2}-\mathrm{TiB}_{2}$ and b) $\mathrm{Zn}-\mathrm{TiO}_{2}-\mathrm{TiB}_{2}-\mathrm{ST}$ micrographs after corrosion in $3.65 \% \mathrm{NaCl}$.

\section{Conclusions}

$\mathrm{Zn}-\mathrm{TiO}_{2}-\mathrm{TiB}_{2}$ and $\mathrm{Zn}-\mathrm{TiO}_{2}-\mathrm{TiB}_{2} / \mathrm{ST}$ were successfully deposited on a mild steel surface with homogeneous deposition.

The EDS of the matrix confirmed the existence of $\mathrm{Zn}$, $\mathrm{Ti}$, and other chemical agents from the organic additive.

The $\mathrm{Zn}-\mathrm{TiO}_{2}-\mathrm{TiB}_{2}-\mathrm{ST}$ matrix revealed an improved corrosion resistance as compared to $\mathrm{Zn}-\mathrm{TiO}_{2}-\mathrm{TiB}_{2}$.

Fluid addition of a natural additive to the electrodeposition bath resulted in a reduced texture, and increased micro hardness properties.

Good anti-wear properties were attained on the deposit.

\section{Acknowledgments}

The funding from the National Research Foundation is highly appreciated, and the authors wish to acknowledge the equipment support by Surface Engineering 
Research Centre (SERC), Tshwane University of Technology Pretoria, South Africa.

\section{References}

1. Popoola API, Fayomi OSI, Popoola OM. Int $\mathbf{J}$ Electrochem Sci. 2012;7:4898.

2. Tiwari SK, Sahu RK, Pramanick AK, et al. J Surf Coat Technol. 2011;25:4960.

3. Popoola API, Fayomi OSI, Popoola OM. Int J Electrochem Sci. 2012;7:4860.

4. Fayomi OSI, Popoola API. Int J Electrochem Sci., 2012;7:6555.

5. Lekka M, Kouloumbi N, Gajo M, et al. Electrochim Acta. 2005;50:4551.

6. Popoola API, Fayomi OS. Int J Electrochem Sci. 2011;6:3254.

7. Arici M, Nazir H, Aksu A. J Alloys Comp. 2011;509:1534.

8. Fayomi OSI, Popoola API. Res Chem Intermed. 2013;39:6.

9. Yan GG, Chai S, Xiong X, et al. Trans Nonferrous Metals Soc China. 2012;22:366.

10. Zhang Z, Leng WH, Shao HB, et al. J Electroanal Chem. 2001;516:127.

11. Malatji N, Popoola API, Fayomi OSI, et al. Int J Adv Manuf Technol. 2016;82:1335.

12. Fayomi OSI, Popoola API. Surf Eng Appl Electrochem. 2015;51:76.

13. Kumar MKP, Venkatesha TV, Pavithra MK, et al. Phys Scr. 2011;84:035601.

14. Tuaweri TJ, Wilcox GD. Surf Coatings Technol. 2006;200:5921.

15. Fayomi OSI, Aigbodion VS, Popoola API. J Fail Anal Preven. 2015;15:54.

16. Wang TG, Jeong D, Liu Y, et al. J Surf Coating Technol. 2012;206:2638.

17. Hammami O, Dhouibi L, Bercot P, et al. Int J Corros Sci. 2012;8:1.

18. Naik YA, Venkatesha TV, Nayak PV. Turk J Chem. 2002;26:725.

19. LeRiche EL, Wang-Pruski G, Zheljazkov VD. Hort Science. 2009;44:1866.

20. Fayomi OSI, Popoola API, Kanyane LR, et al. Results Phys. 2017;7:644.

21. Kanyane LR, Fayomi OSI, Popoola API, et al. Procedia Manuf. 2016;7:584.

22. Munro RG. J Res Natl Inst Stand Technol. 2000;105:709. 